Int. J. Speleol., 23, 3-4 (1994): 179-189. 1995

\title{
A new Jujiroa from Sichuan, China (Coleoptera, Carabidae)
}

\author{
Augusto Vigna Taglianti *
}

\begin{abstract}
SUMMARY
Jujiroa iolandae n.sp. is described from Liujia Cave in China (Sichuan, near Huaying, between Chongqing and Nanchong). Strongly depigmented, with very reduced eyes and markedly elongated appendages, it is well distinguishable from Taiwanese and Japanese species, and from the two previously known species from China. One of these, J. suensoni from Shangxi, is quite different (its doubtful taxonomic position is perhaps to be referred to another genus or lineage); the other, J. rufescens from Jiangxi (Fujian), is more related to the new species, that differs by the longer and more sinuate pronotum, with fore and hind angles much more produced, by the presence of basal pore and the absence of first dorsal seta on elytra, and by the apical tooth acute, long and spine-like.

The new species extends well westwards the range of the genus, hitherto extending from southeastern Japan (five described species from Honshu, Shikoku, Kyushu), to Taiwan (seven species) and, in front, to Chinese Fujian.
\end{abstract}

The genus Jujiroa Uéno, 1952, was described for one species (Sphodropsis nipponicus Habu, 1950) from a southwest Japan cave. Previously suggested as member of the Sphodrini tribe (Habu, 1950; Uéno, 1952; Jedlicka, 1961), it was correctly referred to the Platynini by Uéno (1955), Habu (1978) and Casale (1988). Other species of this genus were later described or recorded from southwestern Japan (Uéno, 1955; Habu, 1978; Takakura, 1987; Nakane, 1989), from Southeast (Jedlicka, 1961) and North China (Kirshenhofer, 1990) and, finally, from the high mountains of Taiwan (Uéno \& Saito, 1991).

The occurrence of Jujiroa in China was established by Casale (1988: 917), pointing out that Taphoxenus (Sphodropsis) rufescens Jedlicka, 1961 is not a Sphodrine, but a Platynine. This species, known

* Dipartimento di Biologia Animale e dell'Uomo (Zoologia), Università di Roma «La Sapienza», Viale dell’Università, 32 - I 00185 Roma. 
on a single female specimen, from Kiangsi (= Jianxsi, southeastern China) is considered by Casale as probably belonging to this genus. According to Uéno \& Saito (1991: 2), his «careful redescription and excellent illustration of the type specimen» allows to state that Jujiroa actually occurs in southeastern China and to suppose a presence also in Taiwan, as verified by Uéno \& Saito (1991).

Another Chinese species, Jujiroa suensoni Kirschenhofer, 1990, was later described, also on a single female specimen, from Shanxi (North China). According to the description and the accompanying photograph by Kirschenhofer (1990), this new species seems to be quite different from all other of the genus, and does not accord with Jujiroa diagnosis. It is a very large (18.8 $\mathrm{mm}$ long) and robust species, with stout appendages and, above all, with simple elytral apex, without sutural denticle protruding: I agree therefore with the opinion of Uéno \& Saito (1991: 2), that suensoni belongs to another line of Platynini.

I recently received a sample of two beetles collected in a cave during the speleological expedition to China ("Sichuan '93 Project») organized by the Gruppo Grotte Ragusa, Italy. With an unidentified Alleculidae beetle, not belonging to the cave fauna, one Carabidae specimen appeared to be a true Jujiroa, very similar to rufescens: this Sichuan specimen (examined also by A. Casale) belongs to a new species, the second high specialized cave Platynine from China, extending northwards and westwards the range of the genus.

\section{Jujiroa iolandae n.sp.}

\section{Diagnosis}

A medium sized (14.5 mm long) species, light reddish brown, with long head, microphthalmic; long, narrow and sinuate pronotum, with sharply protruding acute fore and hind angles; elytra produced in an apical denticle, strong and spine-like; very long antennae; long and slender appendages, tarsi strigose.

Very similar to rufescens, the new species is easily recognizable by the longer and more sinuate pronotum, with much more protruding acute angles, the shape of apical spine, the presence of basal pore and the absence of the first dorsal pore on elytra (Fig. 1). 


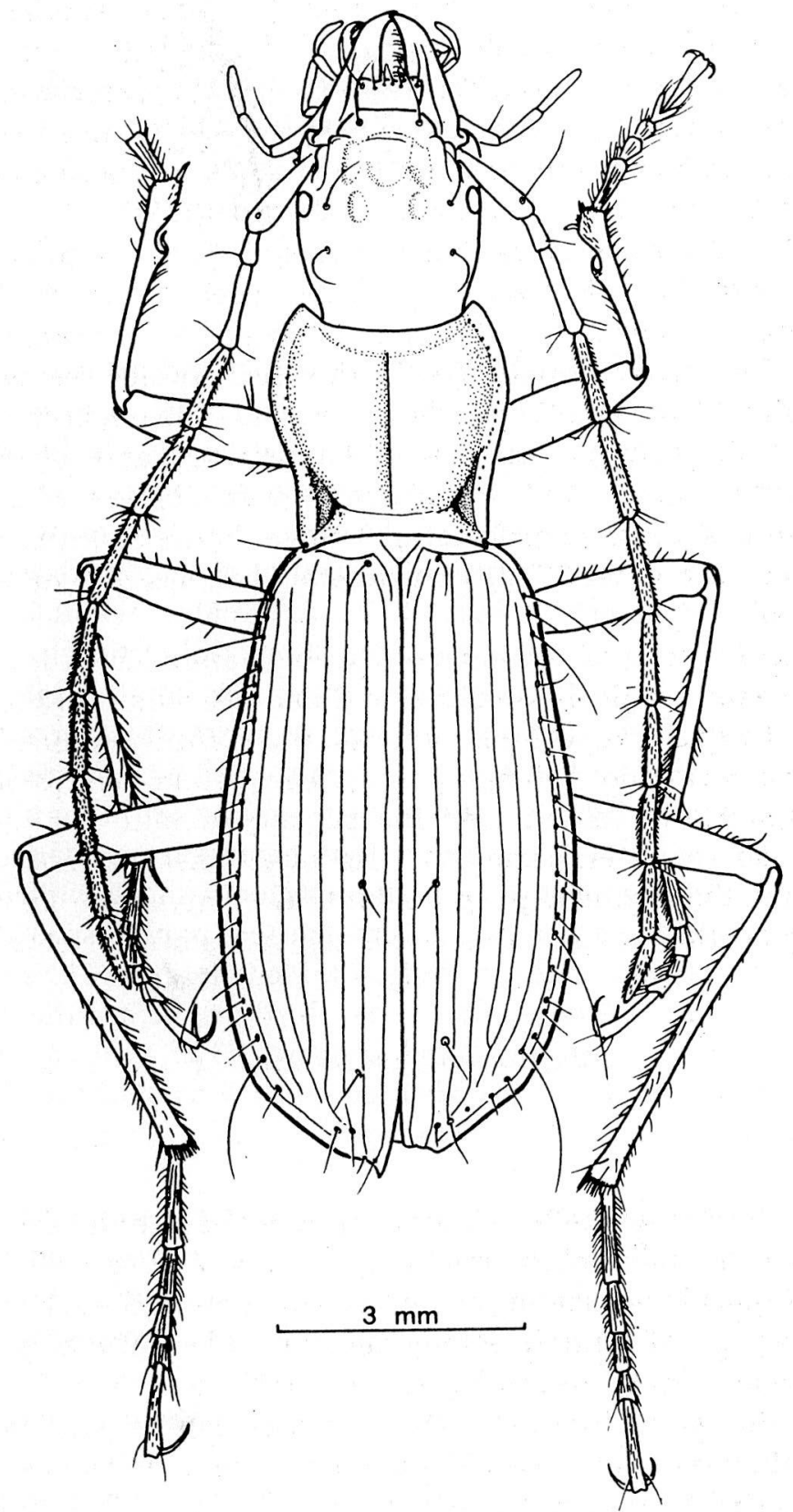

Fig. 1 - Jujiroa iolandae n.sp., from Liujia Cave in Sichuan, holotype: habitus. 


\section{Type material}

Holotype: female, China, Sichuan, Huaying, 810 m, Liujia Cave, 12.VIII.1993, I. Galletti leg., in Coll. Vigna Taglianti, at the Zoological Museum of Rome University.

\section{Description}

Total lenght $14.5 \mathrm{~mm}$ (13.2 $\mathrm{mm}$ from apical margin of clypeus to apical spine of elytron). Concolorous light reddish brown. Microsculpture in fine, almost faint polygonal meshes on the head, obsolete on the vertex, shiny; fine transverse meshes on pronotum; more evident isodiametrical meshes on the elytra, more or less sericeous.

Head ovoid, longer than wide (maximum lenght, from apical margin of clypeus to pronotum, $2.75 \mathrm{~mm}$; greatest widht $2.25 \mathrm{~mm}$, behind eyes); frontal impressions light, short, right, ending in a shallow round fovea at posterior level of eyes; eyes small, slightly convex; genae long, feebly convex; two pairs of supraorbital setae on parallel lines; neck well marked, with rather shallow constriction; labrum transverse, with the apical margin sinuate, trifid for a median projection; mandibles long, rather right; postmentum quadrisetose, with longer inner setae, mentum bisetose, tooth sharply bifid at the tip; glossa bisetose, apically tranverse cutted, paraglossae slender, slightly arcuate; antennae very long, total lenght about $11.5 \mathrm{~mm}$, reaching apical fifth of elytra.; scape and third article are the longest, subequal in lenght, segment 2 the shortest, $1 / 3$ of 1 and 3 , segment 4 (the first pubescent) more or less equal as 3, as also 5 and 6, 7-10 gradually decreasing, cylindrical, and terminal, conical, sligtly longer than 10 .

Pronotum subcordate, narrow, a little wider than long and than head greatest width, about equally narrowed in front and behind: $2.55 \mathrm{~mm}$ long (along the mid-line), basal width equal as head greatest width, fore width a little lesser $(2.1 \mathrm{~mm})$, the greatest width 2.9 $\mathrm{mm}$ (at about two-thirds from base); tergum gently convex, disc depressed, median line well marked, not reaching the two margins; sides widely reflexed throughout, arcuate in front, sinuate at middle, right and parallel towards hind angles; lateral furrows large and deep, smooth, with a side-parallel row of points, marginal, in each furrow; basal furrow large and deep, smooth, with basal foveae 
clearly point-shaped; anterior pair of setae absent, postangular pair present, at the hind angles; anterior margin truncate at middle, front angles triangular, acute, sharply produced forwards; base slightly arcuate, hind angles triangular, acute, sharply produced backwards, apically denticle like. Prosternum glabrous, with apophysis depressed, simple, posteriorly narrow, but not sharply edged.

Elytra elongated ( $8 \mathrm{~mm}$ long), wider than pronotum, narrow at base and gradually dilated towards the middle which is the widest ( $4.4 \mathrm{~mm}$ together); basal border posteriorly arcuate, obtuse angulate at the base of third and sixth interval; lateral border rounded at shoulders, effaced; gently sinuate at fore fifth, regularly rounded behind, to the apical sixth; then right and slightly sinuate to the apex; median border a little abbreviate and apically divergent; apex acute, not truncate, mucronate, ending in a strong, acute produced, spinelike tooth; dorsum gently convex; striae well impressed, fairly punctate; intervals slightly convex; basal pore present, at the base of stria 1 ; interval 3 with two pores, one behind the middle, one at about the apical fifth; marginal series of umbilicate pores 22 in number, the setae $3 \mathrm{rd}, 15 \mathrm{th}, 20$ th being the longest; apical pores 4 in number, one at the apex of interval 3 , another at the same level in the apical part of interval 7, and two marginal, shorter, at the outer base of the spine, at the end of striáe 1 and 2 .

Wings reduced, about to the lenght of metanotum.

Ventral surface glabrous; sternites bisetose; anal sternite subtruncate at the apex, quadrisetose.

Legs very elongated, especially in hind femora and tibiae (hind tibiae $4.2 \mathrm{~mm}$ long); tarsi slender, upper side glabrous, with deep longitudinal striae; segment 4 bilobed in pro- and mesotarsi, emarginate in metatarsus; segment 5 without secundary setae on the dorsal side.

Female genital appendages (Figs. 2-3) of Platynine (sensu stricto) type; penultimate segment of gonostyli with normal fringe of setae on ventral surface; apical segment elongated, simple, gently curved, without dorsal seta, bearing three short lateral spines.

Male unknown. 

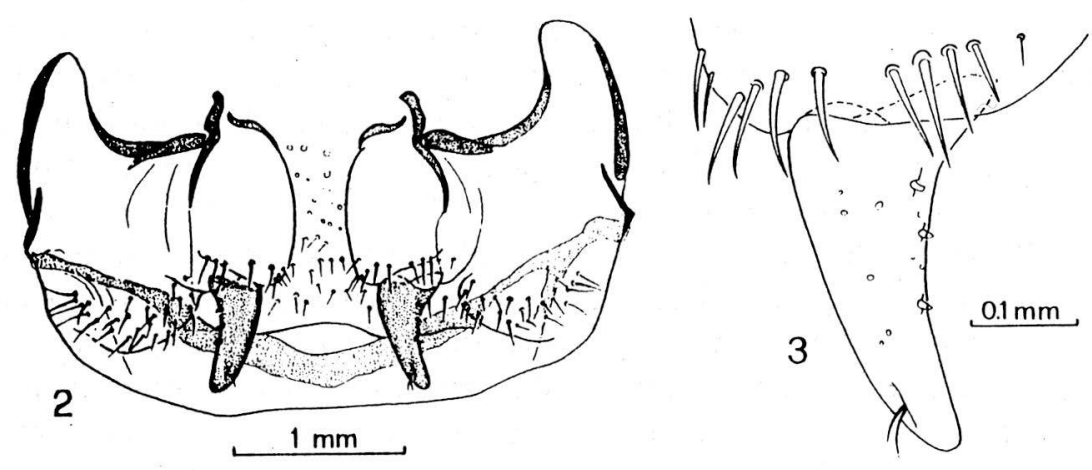

Figs. 2-3 - Jujiroa iolandae n.sp., holotype: genital appendages (2) and left gonostylus, at major magnification (3).

\section{Derivatio nominis}

It is a pleasure to dedicate this new species, one of the very few specialized cave carabids hitherto known from China, to its lucky and kind collector, dr Iolanda Galletti.

\section{Ecological notes}

The type locality, Liujia Cave, is located in the Huaying Area (Sichuan, China), $810 \mathrm{~m}$ in altitude, about $80 \mathrm{~km}$ northwards of Chongqing and southwards of Nanchong, and about $250 \mathrm{~km}$ eastwards of Chengdu.

The cave, of fossil type, with only few dropping sites and pools, is $382 \mathrm{~m}$ long and $60 \mathrm{~m}$ deep. It is formed by a main tunnel, almost straight, westwards directed, smoothly descending in the first $50 \mathrm{~m}$, followed by a rising ground for $15 \mathrm{~m}$, southwards, and by a plain tunnel, $30 \mathrm{~m}$ long, southwestwards, with water pools, and some lateral pits. After this point, the main corridor descends rightly, on fallen stones, in the same southwest direction, for other $130 \mathrm{~m}$. Around 50 $\mathrm{m}$ before the end, another corridor begins on the right, turning back northeastwards, for other $100 \mathrm{~m}$ with a halfway crossing shorter tunnel, eastwards directed. 
From the ecological point of view, this cave seems to belong to the temperate type, rather dry $(83 \%$ humidity $)$ and warm $\left(14^{\circ} \mathrm{C}\right.$ water). The fauna seems rather poor, with few moths, crickets, millipeds, snails, but also with highly specialized elements, at least in the aquatic fauna, such as the Amphipoda Gammaridae (see Karaman \& Ruffo, 1995, in this volume).

The unique specimen of Jujiroa iolandae n.sp. was found on the soil, in the rising ground before the water pools, at about $70 \mathrm{~m}$ from the entrance. The morphological features of this species, at a very high degree of specialization in adaptation to the subterranean life (i.e. depigmentation, microphthalmy, long and slender appendages, complete reduction of wings), suggest to consider it as a true cave dweller.

\section{Remarks}

Jujiroa iolandae n.sp. is similar to rufescens in its general facies: medium sized $(14.5 \mathrm{~mm})$, with elongated and slender body, concolorously reddish brown; long head, little eyes, constricted neck, the same shape of labium and ligula; pronotum lacking in fore lateral seta; elytra not truncate at the apices, but ending with spine; very long appendages, strongly strigose tarsi with bilobed fourth article.

It differs in shallower frontal impressions, much longer antennae (reaching the apical fifth of elytra); pronotum longer, with more strongly sinuate lateral sides and much more protruding and acute both fore and hind angles; elytra with more protruding, acute and spine-like apical denticle; basal pore present at the base of the first interval, the third one with only two dorsal pores, lacking in first: one after the middle, one about at the apical fifth.

As pointed out by Uéno \& Saito (1991: 6) J. rufescens seems to be closer to J. nishikawai than to other Taiwanese and Japanese species: but nishikawai, bearing a basal pore at the base of the first elytral interval and two pores on the third at about middle and apical fifth (as in iolandae), clearly differs in elytra truncate at the apices, as is usual in the Taiwanese species, and especially in the shape of pronotum, with rounded apical and basal angles.

It can be clearly argued that Jujiroa iolandae n.sp. belongs to the same species-group as J. rufescens (Jedlicka, 1961). Though each 
of these two species are so far known from only single female specimens, they are easily recognizable by morphological characters and they are geographically separated from each other.

The locality of Jujiroa rufescens, from "Süd China: Kiansi - Fuceu», according to Uéno \& Saito (1991: 2), may be on the Wu-Yi Mountains (Wuyi Shan) between Jiangxi (= Kiangsi) and Fuzhou, in Fujian; the locality of $J$. iolandae is the Liujia Cave, near Huaying, lying between Nanchong and Chongqing, in Sichuan, very widely distant to the northwest, more than $1000 \mathrm{~km}$, from the previous locality.

With the finding of this new species, the wide distribution of the genus Jujiroa is stretched well westwards: from Japan, in the southwestern Honshu, eastwards to the Tenryû-gawa drainage area (Aichi Pref.), along the Pacific side, to the Kii Peninsula (Ise in the Mie Pref.), to the Islands of Shikoku and Kyushu, westwards to the Gotô Islands; in near all the high mountain of Taiwan; in southeastern China, in Jiangxi, and finally to western China, in Sichuan (Fig. 4).

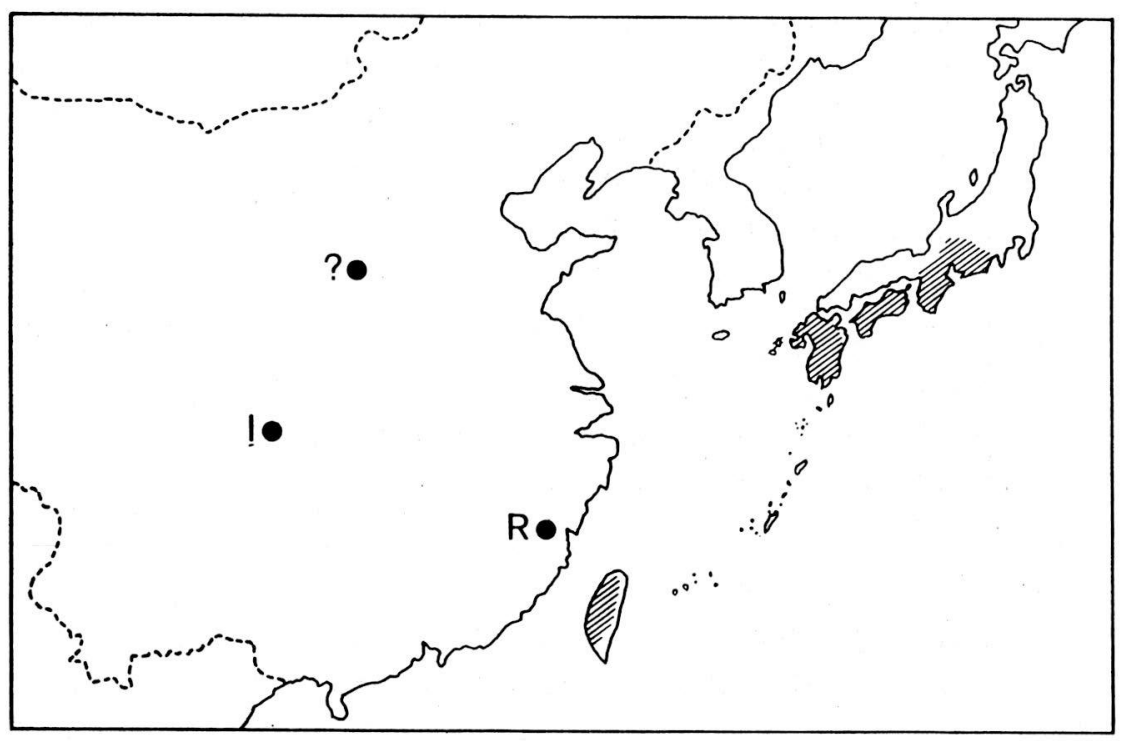

Fig. 4 - Distribution of the genus Jujiroa: $\mathrm{R}=$ rufescens, $\mathrm{I}=$ iolandae, ? $=$ "Jujiroa» suensoni. 
If $J$. suensoni really belongs to this genus, its locality, Mian Shan in Shanxi, appears to be very distant to the north from both the «true» Jujiroa Chinese species: about $1300 \mathrm{~km}$ northwards from $J$. rufescens and about $1000 \mathrm{~km}$ northeastwards from J. iolandae. Not only, but the Shanxi region, clearly palaearctic, in NorthCentral China, is well known to be quite different, from the zoogeographical point of view, from the «transitional zone» SichuanHubei-Hunan-Jiangxi of Southern China. These biogeographical remarks support the idea that the northern species belongs to another lineage of Platynini.

\section{CATALOGUE}

Jujiroa Uéno, 1952

A. Japan species (from caves and upper hypogean zone)

1. nipponica (Habu, 1950)

SW Japan, Shikoku, Kochi Pref.

Ryugado Cave, Kagami

(limestone cave)

2. troglodytes Uéno, 1955

Japan, Honshu, Aichi Pref.

Ja-ana Cave, Shin-ana Cave

(limestone caves)

3. elongata Uéno, 1955

Japan, Honshu, Mié Pref.

Gochigoé-no-yoko-ana, Oshawa-no-kaza-ana,

Kuradani-no-ana Caves, Ise

(limestone caves)

4. onoi Takakura, 1987

Japan, SE Kyushu

(evergreen broadleaved forest) W Kyushu

5. ikezaki Nakane, 1989

Gotô Is.

(lava cave) 
6. "an undescribed species" (cfr. Uéno \& Saito, 1991)

B. Taiwan species

(not from caves, but in alpine zone)

6. nishikawai Uéno \& Saito, 1991

Central Taiwan

Mt. Hsiao-hsüeh Shan 2630 m Mt. An-ma Shan 2630 m

(Ta-hshüeh, Ho-p'ing Hsiang)

7. rectangulata Uéno \& Saito, 1991

Northern Taiwan

Mt. T'ai-p'ing Shan $1200 \mathrm{~m}$

(Ta-t'ung Hsiang)

8. orthogenys Uéno \& Saito, 1991

Central Taiwan

Mt. Mao-mu Shan 2550 m

(Jen-ai Hsiang)

9. alticola Uéno \& Saito, 1991

Northern Taiwan

Mt. Nan-hu-ta Shan $3250 \mathrm{~m}$

(Ho-p'ing Hsiang)

10. shihi Uéno \& Saito, 1991

Central Taiwan

Mt. Cho-she-ta Shan 2130-2150 m

(Jen-ai Hsiang)

11. longa Uéno \& Saito, 1991

Southern Taiwan

Hsiang-yang $2140 \mathrm{~m}$

(Mt. Kuan-shan, Hai-tuan Hsiang)

12. parvicollis Uéno \& Saito, 1991

Central Taiwan

Mt. Cho-she-ta Shan $2130 \mathrm{~m}$

(Wu-chieh Lin-tao,Jen-ai Hsiang) 


\section{China (from caves or uncertain)}

13. rufescens (Jedlicka, 1961)

S China, Kiansi (= Jiangxi)

Fuceu (Wu-Yi Mt. ?)

(limestone cave ?)

14. iolandae Vigna Taglianti, 1995

China, Sichuan

Liujia Cave, Huaying

(limestone cave)

?. suensoni Kirshenhofer, 1990

China, Shanxi

Mien Shan (= Mian Shan) $37^{\circ} \mathrm{N} 112^{\circ} 30^{\prime} \mathrm{E}$

(limestone cave ?)

\section{ACKNOWLEDGEMENTS}

I am indebted to dr Iolanda Galletti, biologist, and the other speleologists of the Gruppo Grotte Ragusa, Centro Ibleo di Ricerche Speleo-Idrogeologiche, for collecting the biological samples during the «Sichuan ' 93 Project» expedition, and for providing the relevant geographical and ecological informations. Aknowledgements are also due to prof. Marcello La Greca, for giving me the sample of Carabids, to prof. Achille Casale, for friendly pushing me to publish this note and for useful suggestions and discussions and to prof. Valerio Sbordoni, for the revision of the manuscript. I am also indebted to dr Shun-Ichi Uéno, for sending me his papers on this subject and to dr Niccolò Falchi, for the kind help in the illustrations.

\section{REFERENCES}

CASALE, A. 1988. Revisione degli Sphodrina (Coleoptera, Carabidae, Sphodrini). Mus. reg. Sci. nat., Torino, Monogr., 5: ii + 1024 pp.

HABU A. 1950. On some cave-dwelling Carabidae from Japan (Coleoptera). Mushi, Fukuoka, 21: 49-53, pls. 8-10.

HABU, A. 1978. Carabidae: Platynini (Insecta: Coleoptera). Fauna Japonica. Keikagu Publishing, Tokyo, ix +447 pp., 36 pls.

JEDLICKA, A. 1961. Monographie der paläarktischen Taphoxenus-Arten (Coleoptera-Carabidae). Acta entomol. Mus. nat. Pragae, 34: 167-219.

KARAMAN, G. \& RUFFO S. 1995. Sinogammarus troglodytes n.gen. n.sp. A new troglobiont Gammarid from China (Crustacea Amphipoda). Int. J. Speleol., 23 (1994):

KIRSCHENHOFER, E. 1990. Neue Platynini aus China und Korea (Coleoptera, Carabidae). Z. Arb-gem. österr. Entomol., 42: 15-21.

NAKANE T. 1989. Notes on some little-known beetles (Coleoptera) in Japan. 5. KitaKyûshû no Konchû, Kokura, 36: 143-152, pl. 11. (in Japanese, with English descriptions).

TAKAKURA, Y. 1987. Description of a new species of the genus Jujiroa from Kyushu, Japan (Coleoptera, Harpalidae). Kita-Kyûshû no Konchû, Kokura, 36: 177-178. (in Japanese, with English descriptions). 
UENO, S. - I. 1952. On a cave-dwelling Sphodrid found in Japan (Coleoptera, Harpalidae). Mishu, Fukuoka, 24: 17-19.

UENO, S. - I. 1955. New cave-dwelling Anchomenids of Japan. Opusc. entomol., 20: 56-64, pl. 1.

UENO, S. - I. \& A. SAITO 1991. Occurrence of Jujiroa (Coleoptera, Carabidae) on the High Mountains of Taiwan. J. speleol. Soc. Japan, 16: 1-28. 